VER.HCl nhân. Pellet VER.HCl bào chế theo công thức CT $1.12(300 \mathrm{~g} / \mathrm{mẻ})$ được sấy ở 50$55^{\circ} \mathrm{C} / 8$ giờ, rây chọn và đánh giá giá một số chỉ tiêu khác thu được các kết quả như bảng 11.

\begin{tabular}{|c|c|}
\hline Đăc tính & Kết quả \\
\hline Hình thức & $\begin{array}{l}\text { Pellet tròn đều, bề } \\
\text { mặt nhẵn, mịn, kích } \\
\text { thước } 0,8-1,2 \text { mm }\end{array}$ \\
\hline $\begin{array}{l}\text { Khối lượng riêng biếu } \\
\text { kiến }(\mathrm{g} / \mathrm{ml})\end{array}$ & $0,72 \pm 0,06$ \\
\hline Tốc độ chảy $(\mathrm{g} / \mathrm{s})$ & $0,74 \pm 0,09$ \\
\hline Độ mài mòn (\%) & $0,22 \pm 0,08$ \\
\hline Hàm ẩm (\%) & $2,86 \pm 0,11$ \\
\hline $\begin{array}{l}\text { Hàm lượng VER.HCl } \\
\text { trong pellet (\%) }\end{array}$ & $38,45 \pm 0,57$ \\
\hline $\begin{array}{c}\text { Tỷ lê pellet có kích } \\
\text { thước } 0,8-1,2 \mathrm{~mm}(\%)\end{array}$ & $77,22 \pm 1,10$ \\
\hline \multicolumn{2}{|l|}{ Độ hòa tan (\%): } \\
\hline 10 phút & $80,76 \pm 1,51$ \\
\hline 20 phút & $93,38 \pm 1,57$ \\
\hline 30 phút & $97,33 \pm 0,90$ \\
\hline & $99,91 \pm 1,56$ \\
\hline
\end{tabular}

Nhận xét: Pellet thu được đem lấy phân đoạn có kích thước trong khoảng $0,8-1,2 \mathrm{~mm}$ và đem đánh giá thử độ hòa tan các thời điểm lây mẫu là: $10,20,30$ và 60 phút. Pellet VER. $\mathrm{HCl}$ nhân bào chế theo phương pháp đùn tạo câu (CT1.12) thì sau 30 phút VER.HCl nhân gẩn như đã được giải phóng hoàn toàn, pellet VER.HCl nhân chưa có khả năng kéo dài giải phóng dược chất. Các pellet đạt các chỉ tiêu trên sẽ được sử dụng để bao kiểm soát giải phóng.

\section{KẾT LUÂN}

- Đã khảo sát và đánh giá được ảnh hưởng của thành phần công thức đến tính chất của pellet VER. $\mathrm{HCl}$ nhân gồm có: Verapamil $\mathrm{HCl}$, Avicel PH102, Lactose, Talc, HPMC E6 và nước tinh khiết. Ảnh hưởng thông số qui trình thiết bị gồm có: Tốc độ tạo câu và thời gian tạo cầu

- Trên cơ sở các kết quả khảo sát ảnh hưởng của các yếu tố đến tính chất của pellet VER.HCl nhân, đã xây dựng được tính chất cho pellet nhân như bảng 11 .

\section{TÀI LIẸU THAM KHẢO}

1. Bộ Y tế (2009), Dược lý học, NXB Giáo dục Việt Näm, Hà Nội, 72-74.

2. Martindale The Complete Drug Reference (2014) Thirty-eighth Edition 1522-1526.

3. BNF 73 (2017) Monograph: Verapamil hydrochloride, Pharmaceutical Press, London, 155-156.

4. Bhalekar M. R., Avari J., Umalkar R. A. (2007), Preparation and in vitro Evaluation of Sustained Release Drug Delivery System for Verapamil HCl, Indian J. Pharm. Sci., 69 (3): 418-422.

5. Nitin D. J., Dipak D. G., Ashish A. H. et al. (2010), Formulation development and evaluation of sustained release pellets of verapamil hcl, International Journal of Pharma Research and Development, 1(11): 1-7.

6. USP 41-NF 36 (2018), Monographs:Verapami hydrochlorid extended release tablets, 4307-4311.

\title{
NGHIÊN CỨU IN VITRO KHẢO SÁT TÌNH TRANG GÃY DỤNG CỤ TRONG SỬA SOẠN ỐNG TỦY Ở HỆ THỐNG TRÂM PROTAPER QUAY TAY
}

\section{TÓM TẮT}

Mục tiêu: Nghiên cứu nhằm khảo sát tình trạng gãy dụng cụ trong sửa soạn ống tủy ở hệ thống trâm Protaper quay tay. Đối tượng và phương pháp: Nghiên cứu in vitro được thực hiện trên 50 ống tủy gần (bao gồm cả ngoài gần và trong gần) của chân gân răng cối lớn hàm dưới ở người trưởng thành, chân răng nguyên ven, đã đóng chóp, có ống tuý cong trong khoảng $10^{\circ}-40^{\circ}$ theo phương pháp Schneider 1971. Các ống tủy gân được sửa soạn tới dụng cụ F3.

* Đai hoc Y Dược TP Hồ Chí Minh

Chịu trách nhiệm chính: Nguyễn Thu Thủy

Email: ntthuy@ump.edu.vn

Ngày nhậ bài: 5/3/2021

Ngày phản biên khoa hoc: 1/4/2021

Ngày duyệt bài: 3/5/2021

\section{Nguyễn Thu Thủy*}

Mỗi bộ protaper sẽ được thao tác cho đến khi có dụng cụ trong bộ đang thực hiện bị gãy. Số lượng ống tủy đã̃ được thao tác ở mối bộ sẽ được ghi nhận. Răng có chứa mảnh gãy sẽ được phân tích qua phim Cone Beam Computed Tomography Scan (CBCT) để xác định độ dài mảnh gãy, đồng thời xác định tương quan của mảnh gãy với chóp răng và miệng lố tủy. Kết quả: Số lượng ống tủy được sửa soạn tối đa là $10 \pm 2.7$ ống tủy. Chiêu dài mảnh gãy trung bình là $2.13 \pm 1.26 \mathrm{~mm}$. Khoảng cách trung bình từ đỉnh mảnh gãy tới chóp răng là $3.09 \pm 1.60 \mathrm{~mm}$. Khoảng cách trung bình từ đâu mảnh gãy tới miệng ống tủy là $5.97 \pm 1.84 \mathrm{~mm}$. Dụng cụ có suất độ gãy nhiều nhất là trâm S1. Kết luân: Khả năng gãy ở hệ thống trâm Protaper quay tay xảy ra khi dụng cụ đã sứa soạn $10 \pm 2.7$ ống tủy. Không có dụng cụ nào bị gãy trong lần sửa soạn đâu tiên. Dụng cụ có suất độ gãy nhiều nhất là trâm S1. Khi sự cố gãy dung $\mathrm{cụ} \mathrm{xảy} \mathrm{ra,} \mathrm{chiều}$ 
dài mảnh gãy trung bình là $2.13 \pm 1.26 \mathrm{~mm}$. Mảnh gãy thường có xu hướng nằm gần về phía chóp răng hơn là phía miệng ống tủy.

Tư khóa: Sửa soạn ống tủy, gãy dụng cụ, hệ thống trâm Protaper quay tay

\section{SUMMARY}

\section{AN IN VITRO STUDY ON INSTRUMENT FRACTURE IN PREPARINGDENTAL ROOT CANALS WITH MANUAL PROTAPER SYSTEM}

Objective: This study aimed to investigate the instrument fracture in preparing root canalswith manual Protaper system. Materials and methods: This in vitro study was carried out on 50 proximal canals (including the buccal-mesial and lingual-mesial canals) of the mesial root of lower molars in adults; the rootswere intact and apically closed, with canal curving in the range $10^{\circ}-40^{\circ}$ according to the Schneider 1971 method. Mesial canals were prepared to the F3 instrument. Each protaper set would be manipulated until the tool in the working set broke down. The number of canals manipulated in each set would be recorded. Tooth containing the fracture were analyzed through Cone Beam Computed Tomography Scan (CBCT) to determine the length of the fracture, and also to investigate the correlation of the fracture with the tip and the canal entrance dimension. Result: The maximum number of prepared canals was $10 \pm 2.7$ canals. The average fracture length was $2.13 \pm 1.26 \mathrm{~mm}$. The average distance from the top of the fragment to the tip of the tooth was $3.09 \pm$ $1.60 \mathrm{~mm}$. The average distance from the tip of the fragment to the entrance of the canal was $5.97 \pm$ $1.84 \mathrm{~mm}$. The instrument with the highest fracture rate was file S1. Conclusions: The possibility of fracture in the manual Protaper file system occurs when the instrument has compiled $10 \pm 2.7$ canals. No tools were broken during first preparation. The instrument with the highest fracture rate is file $\mathrm{S} 1$. When tool breakage occurs, the average fracture length is $2.13 \pm$ $1.26 \mathrm{~mm}$. The fracture tends to be closer to the tip of the tooth than towards the entrance of the canal.

Keywords; Reparing root canals, instrument fracture, manual Protaper system.

\section{I. ĐĂT VẤN ĐỀ}

Nội nha là một ngành khoa học nha khoa, nghiền cứu bênh căn, chẩn đoán, dự phòng và điêu trị các bệnh lí của tủy răng, mô quanh chóp và các biến chứng[1]. Mục tiêu của công việc điều trị nội nha bao gồm: loại bỏ mô bênh, vi khuẩn và sản phẩm vi khuẩn trong hê thống ống tủy; tạo dạng và trám bít toàn bộ hệ thống ống tủy; tái tạo thân răng để ngăn ngửa tái nhiễm sau điều trị [2]. Tạo dạng ống tủy là giai đoạn quan trong nhất trong quá trình điều trị nội nha [3].Nhiều tác giả và các nhà lâm sàng đều công nhận ảnh hưởng quan trọng của việc sửa soạn ống tủy đối với kết quả lẩm sàng, phương pháp thực hiên và sinh học trong điều trị nội nha [4]. Đây là giai đoạn gây nhiều thử thách nhất và tốn nhiều thời gian nhất đối với các bác sĩ lâm sàng.

Sự phát triển của khoa học và công nghệ trong nha khoa đã giúp cải tiến và hoàn thiện các loại dụng cụ trong sửa soạn ông tủy.Từ khi ra đời đến nay, hê thống dung $\mathrm{cu}$ NickelTitanium đã thể hiên nhiều ưu điểm của mình và trở nên rất phổ biển trong thủ thuât nội nha. Hê thống dụng cụ NiTi được đánh giá có hiệu quả trong việc cải thiện hiệu quả quá trình tạo dạng ống tủy, đặc biệt là với các ống tủy cong[5]. Tuy nhiên, cũng nhứ các dụng cụ khác, hệ thống này cũng không tránh khỏi được các sự cố trong thực hành nha khoa như: gãy dụng cự, tao khấc, loe rách chóp, làm thẳng ống tủy, thủng ống tủy, thủng chóp, tạo khuỷu và tắc nghẽn vùng chóp. Trong tất cả các sự cố có thể gặp, gãy dung cu là tình huống tao nhiều áp lực cho các bác sĩ lầm sàng cũng như gây tâm lý lo lắng cho bệnh nhân nhất. Các dụng cụ quay NiTi bị gãy là một thực tế trong lâm sàng nội nha mà các bác sĩ phải đối mắt [6]. Hê thống dung cư NiTi có nhiêu sản phẩm khác nhau như: hệ thốngProtaperquay tay và quay máy, hệ thống Protaper Next quay máy. Trong các sản phẩm trên, Protaper quay tay là sản phẩm được các bác sĩ ưa chuộng và ứng dụng nhiều trong lâm sàng. Việc thực hành nội nha với hệ thống trâm Protaper quay tay có nhiều yếu tố nguy cơ dẫn đến sự cố và thất bai trong điều trị nọi nha, trong đó gãy dụng cụ là một trong những sự cố thường thấy nhất trên lâm sàng.

Với những lý do trên, chúng tôi tiến hành thực hiện nghiên cứu thử nghiệm in vitro: "Nghiên cứu in vitro khảo sát tình trạng gãy dụng cụ trong sửa soạn ống tủy ở hệ thống trâm Protaper quay tay" với mục tiêu: Khảo sát tình trạng gãy dụng cụ trong sửa soạn ống tủy ở hệ thông trâm Protaper quay tay.

\section{II. ĐỐI TƯợNG VÀ PHƯƠNG PHÁP NGHIÊN CỨU 2.1. Đối tượng nghiên cứu \\ Tiêu chuẩn chon mẫu. Thu thập mẫu} nghiên cứu gồm 50 răng cối lớn hàm dưới được nhổ không liên quan đến vấn đề nghiên cứu:

- Răng có giải phẫu chân răng bình thường, chân răng nguyên vẹn. Răng đã đóng chóp.

- Răng không bị calci hóa và không bị tiêu ngót.

- Răng chưa tứng nội nha trước đó. Lố chóp ống gần (bao gồm cả ống ngoài gần và ống trong gần) không cho phép dụng cụ trâm K số 15 vượt qua.

- Răng có ống tủy cong (góc Schneider từ 10$40^{\circ}$ ) theo cách đo độ cong của Schneider (1971) [7]. 


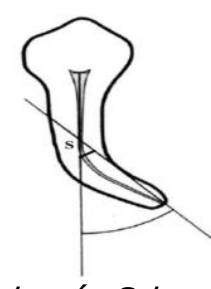

Hình 1. Cách đo góc Schneider được thể hiện trên môt ống tủy [7]

Xử lý và chuẩn hóa mẩu. Răng người đã nhổ được xử lý như sau:

2. Rửa sạch dưới vòi nước và ngâm trong Hexanios 2\%.

3. Bảo quản trong $\mathrm{NaCl} 0,9 \%$ cho đến khi đủ mẫu.

4. Cạo sạch cao răng và mô còn sót lại trên bề mặt chân răng bằng máy lây cao răng siêu âm và các dụng cụ nạo túi nha chu.

- Thiết lập điểm tham chiếu tin cậy để đo chiều dài làm việc.

- Lấy tủy sạch bằng trâm gai (Dentsply Maillefer, Ballaigues, Switzerland).

- Thăm dò ống tủy với trâm dũa K 08 hoặc 10 (Dentsply Maillefer, Ballaigues, Switzerland).

- Tạo đường trượt bằng trâm $\mathrm{K}$ số 15 cho tất cả các ống gần. Các răng có lỗ chóp ống gần bị trâm K số 15 vượt qua sẽ bị loại bỏ.

- Chiều dài làm việc được xác định bằng cách trừ đi $1 \mathrm{~mm}$ từ chiều dài quan sát được trâm 10 ló ra khỏi ống tủy.

- Xác định độ cong của ống tửy theo phương pháp Schneider và chọn các mẫu đạt yêu cầu (góc cong từ 10-40 ${ }^{\circ}$.

\subsection{Phương pháp nghiên cứu}

Thiết kế nghiên cứu: Nghiên cứu invitro, phân tích mẫu.

Thiết bị, dụng cụ và vật liệu nghiên cứu

- Máy chụp phim CBCT Galaxis (khoa Răng Hàm Mặt - đại học Y Dược Tp. Hồ Chí Minh)

- Bộ đồ khám, thước nội nha, dụng cụ bơm rửa, tay khoan, các loại mũi khoan

- Bộ trâm dũa $\mathrm{K}$ nhiều kích thước $08,10,15$, 20, 25 (Dentsply - Maillefer, Ballaigues, Switzerland)
- 5 bộ Protaper Dentsply quay tay mới hoàn toàn với đầy đủ các dụng cụ SX, S1, S2, F1, F2, F3.

- Côn giấy

- Chất bôi trơn ống tủy EDTA dạng nhão (Glyde- Dentsply- Maillefer, Ballaigues, Switzerland)

- Dung dich bơm rửa $\mathrm{NaOCl} 2,5 \%$

Qui trình thực hiện gồm các bước sau:

- 5 bộ Protaper quay tay sẽ được hấp dưới áp suất 2.97 atm (3 bar) dưới nhiệt độ $134^{\circ} \mathrm{C}$ trong 7 phút

- Chuẩn bị răng: thao tác sẽ được thực hiện trên bộ trâm quay tay Protaper với các điều kiện sau:

+ Sửa soạn ống tủy: ống gần được sửa soạn tới dụng cụ F3

+ Mối bộ protaper sẽ được thao tác cho đến khi có dụng cụ trong bộ đang thực hiện bị gãy

+ Sau mỗi răng, dụng cụ sẽ được làm sạch và khử trùng bằng gòn tẩm dung dịch $\mathrm{NaOCl}$ $2.5 \%$.

- Số lượng ống tủy đã được thao tác ở mỗi bộ sẽ được ghi nhận

- Răng có chứa mảnh gãy sẽ được phân tích dưới CBCT để xác định độ dài mảnh gãy, đồng thời xác định tương quan của mảnh gãy với chóp răng và lố tủy.

Lưu ý: + Thực hiện thao tác đối với dụng cụ đúng theo hướng dẫn của nhà sản xuất.

+ Sau mỗi lần đổi dụng cụ, bơm rửa ống tủy với $2 \mathrm{ml} \mathrm{NaOCl} 2,5 \%$ bằng ống bơm rửa đặt vào ống tủy sâu nhất có thể mà không dùng lực.

+ Sử dụng 1ml EDTA 17\% cho mối dụng cụ trong quá trình sửa soạn ống tủy.

- Trong quá trình tạo đường trượt, luôn kiểm tra sự thông suốt của ống tủy bằngtrâm dũa $\mathrm{K}$ số 08 hay 10. Thấm khô ống tủy đã sửa soạn bằng côn giấy. Tất cả các ống tủy đều được sửa soạn bởi cùng một người theo đúng hướng dẫn của nhà sản xuất.

- Chiêu dài mảnh gãy dụng cụ và tương quan của nó với ống tủy được xác định trên $\mathrm{CBCT}$ theo phương pháp cộng dồn từng đoạn nhỏ theo đoạn cong của ống tủy (Hình 2).
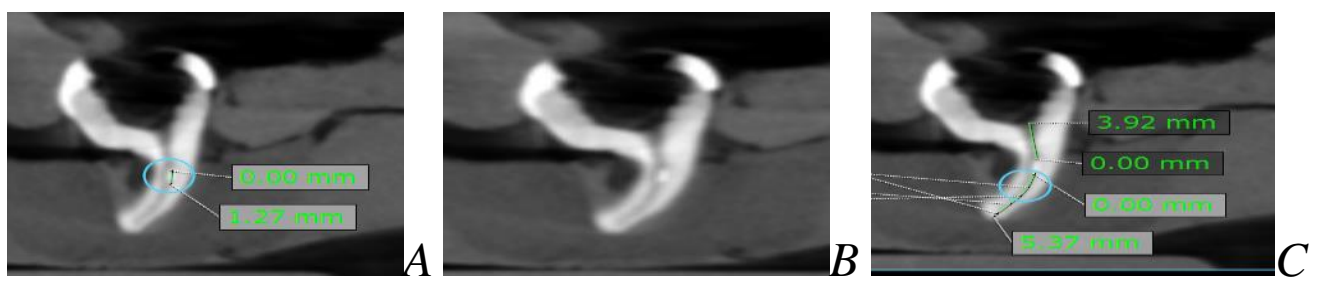

Hình 2. Cách xác định chiều dài của mảnh gãy dụng cụ và tương quan của nó với ống tủy A-Xác định vị trí mảnh gãy, B-Xác định chiều dài mảnh gãy, C-Xác định tướng quan mảnh gãy và ống tửy

2.3. Phương pháp đánh giá và xử lý thống kê. Các số liệu được nhập vào máy tính và xử lý bằng Excel 2010. 


\section{KẾT QUẢ NGHIÊN CỨU}

\subsection{Số lượng ống tủy được sửa soạn tối đa}

- Số lượng ống tủy được sửa soạn tối đa là $10 \pm 2.7$ ống tủy. Không có dụng cụ nào bị gãy trong lần sửa soạn đầu tiên. Kết quả được trình bày ở bảng 1 .

Bảng 1. Số lượng ống tưy được sửa soạn tối đa ở hệ thống trâm Protaper quay tay

\begin{tabular}{|c|c|c|c|c|c|c|}
\hline & N & Trung bình & Độ lệch chuấn & Trung vị & Min & Max \\
\hline Số lượng & 5 & 10.0 & 2.7 & 10 & 7 & 13 \\
\hline
\end{tabular}

\subsection{Chîeu dài trung bình của mảnh gãy}

- Chiều dài mảnh gãy trung bình là $2.13 \pm 1.26 \mathrm{~mm}$. Kết quả được trình bày ở bảng 2 .

Bảng 2. Chiều dài trung bình của mảnh gãy

\begin{tabular}{|c|c|c|c|c|c|c|}
\hline & $\mathbf{N}$ & Trung bình & Độ lệch chuấn & Trung vị & Min & Max \\
\hline Chiều dài mảnh gãy & 5 & 2.13 & 1.26 & 1.80 & 0.94 & 4.51 \\
\hline
\end{tabular}

\subsection{Tương quan của mảnh gãy và ống tủy}

- Khoảng cách trung bình từ đỉnh mảnh gãy tới chóp răng là $3.09 \pm 1.60 \mathrm{~mm}$. Kết quả được trình bày ở bảng 3 .

- Khoảng cách trung bình từ đầu mảnh gãy tới miệng ống tủy là $5.97 \pm 1.84 \mathrm{~mm}$. Kết quả được trình bày ở bảng 4 .

Bảng 3. Khoảng cách trung bình từ đỉnh mảnh gãy đên chóp răng

\begin{tabular}{|c|c|c|c|c|c|c|}
\hline & $\mathbf{N}$ & Trung bình & Độ lệch chuấn & Trung vị & Min & Max \\
\hline $\begin{array}{c}\text { Khoảng cách từ đỉnh mảnh } \\
\text { gãy đến chóp răng }\end{array}$ & 5 & 3.09 & 1.60 & 2.97 & 1.29 & 5.37 \\
\hline
\end{tabular}

Bảng 4. Khoảng cách trung binh từ miệng lố tủy đến đầu mảnh gãy

\begin{tabular}{|c|c|c|c|c|c|c|}
\hline & $\mathbf{N}$ & Trung bình & Độ lệch chuấn & Trung vị & Min & Max \\
\hline $\begin{array}{c}\text { Khoảng cách từ miệng lồ tủy } \\
\text { đến đâuu mảnh gãy }\end{array}$ & 5 & 5.97 & 1.84 & 5.40 & 3.92 & 8.23 \\
\hline
\end{tabular}

3.4. Suất độ dụng cụ bị gãy trong quá trình sửa soạn

- Kết quả ghi nhận của nghiên cứu này ở hệ thống dụng cụ trâm quay tay Protaper, dụng cụ có suất độ gãy nhiều nhất là trâm S1 (Hình 3).

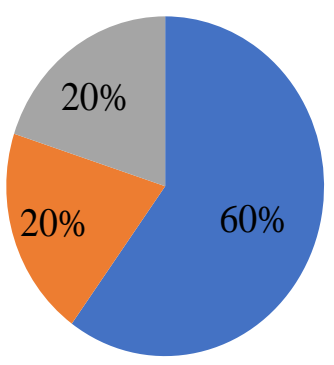

Hình 3. Suât độ dụng cụ bị gãy trong quá trinh sửa soạn

\section{BÀN LUÂ̂N}

4.1. Số lượng ống tủy được sửa soạn và suất độ dụng cụ bị gãy trong quá trình sửa soạn ống tủy. Trong điều kiện thử nghiệm, việc chuẩn hóa mấu khó khăn do răng chỉ được sử dụng một lần và độ cong của ống tủy làm tăng nguy cớ gãy các dụng cụ quay NiTi. Phương pháp Schneider xác định độ cong ống tủy là một trong những phương pháp cổ điển 1971 1nhưng vẫn được nhiều nhà nghiên cứu sử dụng. Tuy rằng xác định độ cong ống tủy theo phương pháp này ít thông tin nhưng cũng giúp nhiêu cho nhà nghiên cứu trong xác định sự khác biệt rõ rệt hay không giữa các nhóm nghiên cứu. Có nhiều phương pháp để đo độ cong ống tủy khác nhau nhưng trong nghiên cứu này chúng tôi sử dung phương pháp Schneider vì đây là một phướng pháp đớn giản mà vẫn hiệu quá và được sử dụng nhiều trong các nghiên cứu về nội nha. Nghiển cứu này được tiến hành trên các rằng có độ cong từ $10^{\circ}-40^{\circ}$. Trên lâm sàng, do sự phức tạp của giải phẫu hệ thống ống tủy nên răng có thể có độ cong nhiều hơn hay có nhiều đoạn cong hơn trong một ống tủy. Hi vọng, trong những nghiên cứu tiếp theo, nếu điều kiện cho phép, chúng tôi sẽ thực hiện trên những răng có những hình thể giải phẫu ổng tủy phức tạp hơn.

4.2. Tương quan mảnh gãy và ống tủy. Có rất ít nghiên cứu đánh giá hậu quả của mãnh gãy dụng cụ với kết quả của công việc điều trị nội nha. Có 2 quan điểm được đưa ra dựa trên các báo cáo lâm sàng: quan điểm đâu tiên cho răng các mảnh gãy khiến cho việc lành thương trở nên chậm hơn, đặc biệt khi mảnh gãy nằm ở vị trí phần ba chóp; quan điểm còn lại cho rằng sự hiện diện của mảnh gãy dụng cụ không ảnh hưởng đến việc lành thương [8]. Grossman 
nghiên cứu và phát biểu rằng không có mối liên hệ có ý nghĩa giữa mảnh gãy dụng cụ với sự lành thương của các tổn thương quanh chóp. Còn Spili và cs (2005) đã thực hiện nghiên cứu và cho thấy rằng mảnh gãy dụng cụ thực sự ảnh hưởng có ý nghĩa đến sự lành thương của các tổn thương quanh chóp. Chính sự mâu thuẫn này làm cho các bác sĩ lâm sàng cần được cung cấp thông tin dựa trên những bằng chứng rõ ràng hơn để đánh giá được nguy cơ tiềm ẩn của sự cố này [8]. Kế hoạch khắc phục hậu quả khi gãy dụng cụ xảy ra về cơ bản có 2 hướng là quyết định để lại mảnh gãy hay thực hiện lấy mảnh gãy ra. Điều này phụ thuộc vào vị trí của mảnh gãy như chúng tôi đã trình bày bên trên.

\section{KẾT LUÂN}

Khả năng gãy ở hệ thống trâm Protaper quay tay xảy ra khi dụng cụ đã sửa soạn $10 \pm 2.7$ ống tủy. Không có dụng cụ nào bị gãy trong lần sửa soạn đầu tiên. Dụng cụ có suất độ gãy nhiều nhất là trâm S1. Khi sự cố gãy dụng cụ xảy ra, chiều dài mảnh gãy trung bình là $2.13 \pm 1.26 \mathrm{~mm}$. Mảnh gãy thường có xu hướng nằm gần về phía chóp răng hơn là phía miệng ống tủy với khoảng cách trung bình từ đỉnh mảnh gãy tới chóp răng là $3.09 \pm 1.60 \mathrm{~mm}$ và khoảng cách trung bình từ đầu mảnh gãy tới miệng ống tủy là $5.97 \pm 1.84 \mathrm{~mm}$.

\section{TÀI LIÊU THAM KHẢO}

1. Hoàng Tử Hùng (2014), "Bài mở đầu nội nha", Giáo trình giảng day bô môn Chữa răng - Nội nha, Đại học Y Dược thành phố Hồ Chí Minh.
2. Đinh Thi Khánh Vân, "Sửa soạn hệ thống ống tủy (Làm sạch và tạo dạng hệ thống ống tủy)", Giáo trình giảng dạy bộ mốn Nội Nha, Đại học Y Dược TPHCM.

3. Berutti Elio, Chiandussi Giorgio, Paolino Salvatore Davide, Scotti Nicola, Cantatore Giuseppe,Castellucci Arnaldo, and Pasqualini Damiano (2012) "Canal Shaping with WaveOne Primary Reciprocating Files and ProTaper System: A Comparative Study."Journal of Endodontics, 38( HYPERLINK "http://www.sciencedirect.com/science/journal/00 992399/38/4" lo "Go to table of contents for this volume/issue" 4 ), pp.505-509

4. Bùi Quế Dương (2008), "Nội nha lâm sàng", Nhà xuất bản Y học xuất bản lần thứ 2, tr. 91-107, tr. 155-165

5. Wu Jintao, Lei Gang, , Yan Ming,Yu Yan, Yu Jinhua, and Zhang Guangdong (2011) "Instrument Separation Analysis of Multi-used ProTaper Universal Rotary System during Root Canal Therapy."Journal of Endodontics, 37(6), pp.758-763

6. Varela-Patin o Purificacio'n, Iban ̃ezPa'rraga Adalce, Rivas-Mundin a Berta, Cantatore Giuseppe, Otero Luis Xose', and MartinBiedma Benjamin (2010) "Alternating versus Continuous Rotation: A Comparative Study of the Effect on Instrument Life."Journal of Endodontics, 36 (HYPERLINK "http:// www.sciencedirect.com/ science/journal/00992399/36/1" Io "Go to table of contents for this volume/issue" 1 ), pp.157-159

7. Schneider S.W. (1971), "A comparision of canal preparation in straight and curved root canals", Oral Surg Oral Med Oral Pathol, 32(2), pp.271-5.

8. Spili Peter, Parashos Peter, and Messer H. Harold(2005) "The Impact of Instrument Fracture on Outcome of Endodontic Treatment". Journal of Endodontics, 31(12), pp.845-850

\section{TÌNH TRẠNG SÂU RĂNG VĨNH VIỄN Ở TRẺ EM VIÊTT NAM NĂM 2019}

\section{TÓM TẮT}

Nghiên cứu nhằm xác định tình trạng sâu răng vĩnh viễn ở trẻ em Việt Nam năm 2019, tữ đó hoạch định các biện pháp dự phòng sâu răng cho trẻ em trong thời gian tới. Nghiên cứu cắt ngang với cỡ mẫu 8053 trẻ em chia làm 4 lứa tuổi $(6-8$ tuổi, $9-11$ tuổi, 12-14 tuổi và 15-17 tuổi) được chọn theo phương pháp ngẫu nhiên, phân tấng nhiều giai đoạn từ 14 tỉnh thành đại diện cho cả nước theo các vùng địa lý. Tình trạng sấu răng ở trẻ em được ghi nhận bởi chỉ số răng sấu - mất - trám (DMFT) và chỉ số mặt

*Bệnh viện Răng Hàm Mặt TU, Hà Nội Chiu trách nhiệm chính: Nguyến Thi Hồng Minh Email: tradentist@gmail.com Ngày nhân bài: 1/3/2021

Ngày phản biên khoa học: 29/3/2021 Ngày duyệt bài: 2/5/2021

\section{Nguyễn Thị Hồng Minh*, Trịnh Đình Hải*}

răng sâu - mất - trám (DMFS) theo tiêu chí của Tồ chức $Y$ tế thế giới kết hợp với chỉ số sâu răng sớm của ICIDAS. Kết quả nghiên cứu cho thấy, sâu răng vĩnh viễn xuất hiện sớm và tăng nhanh theo tuổi. Tỷ lệ sâu răng cao nhất ở nhóm tuối $12-15(43,7 \%)$ và trung bình mối trẻ có một đến hai răng sâu không được hàn, tỷ lệ răng được điêuu trị rất thấp. Kết quả này cho thấy cân đẩy mạnh hơn nữa các biện pháp chăm sóc sức khỏe răng miệng cho trẻ em ở mọi lứa tuổi.

Tư khóa: Sâu răng vĩnh viễn, trẻ em Việt Nam

\section{SUMMARY}

\section{SITUATION OF CARIES IN PERMANENT} DENIIIION IN VIETNAMESE CHILDREN IN 2019

The study aims to identify the situation of caries in permanent dentition in Vietnamese children in 2019, thereby planning measures to prevent dental caries for children in the near future. A cross-sectional study with a sample size of 8053 children divided into age 